\title{
Fundo público e políticas sociais na crise do capitalismo*
}

\section{Public fund and social policies in the crisis of capitalism}

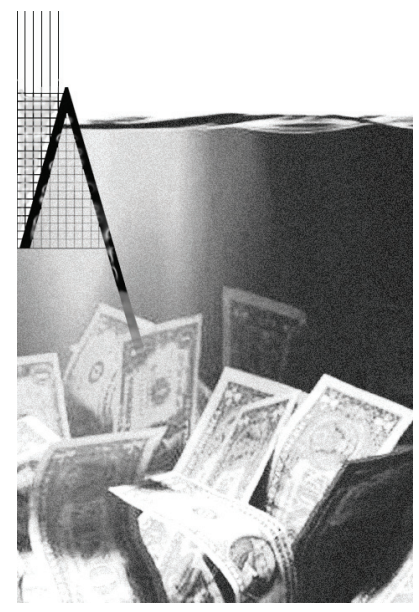

Evilasio Salvador **

Resumo: A característica comum a todas as crises financeiras dos últimos trinta anos é o comparecimento do fundo público para socorrer instituições financeiras falidas durante as crises bancárias, à custa dos impostos pagos pelos cidadãos. Com a financeirização da riqueza, os mercados financeiros passam a disputar cada vez mais recursos do fundo público, impedindo a expansão dos direitos sociais. Este artigo tem por objetivo discutir a crise do capital a partir do papel exercido pelo fundo público e seus rebatimentos no financiamento da seguridade social no Brasil.

Palavras-chave: Crise. Fundo público. Tributação. Seguridade social.

\begin{abstract}
The characteristic that has been common to all financial crises in the last 30 years is the appearance of the public fund to bail out bankrupt financial institutions during the banking crises, at the expense of taxes paid by the citizens. Financing wealth, financial markets dispute resources from the public fund more and more, which impedes the expansion of social rights. This article aims to discuss the crisis of the capital from the role played by public funds and their impact on the financing of social security in Brazil.
\end{abstract}

Keywords: Crisis. Public fund. Taxation. Social security.

* Este artigo é resultado da exposição realizada na mesa "Cenários da crise do capitalismo e as alternativas econômicas e políticas" durante o $3^{\circ}$ Seminário Anual de Serviço Social realizado pela Cortez Editora no dia 10 de maio de 2010, em São Paulo. As reflexões aqui apresentadas estão aprofundadas, em parte, no livro de minha autoria Fundo público e seguridade social no Brasil, publicado pela Cortez em 2010.

** Economista, doutor em política social; professor do Departamento de Serviço Social e do programa de pós-graduação em Política Social da Universidade de Brasília (UnB), Brasília/DF, Brasil. E-mail: evilasiosalvador@gmail.com. 


\section{Introdução}

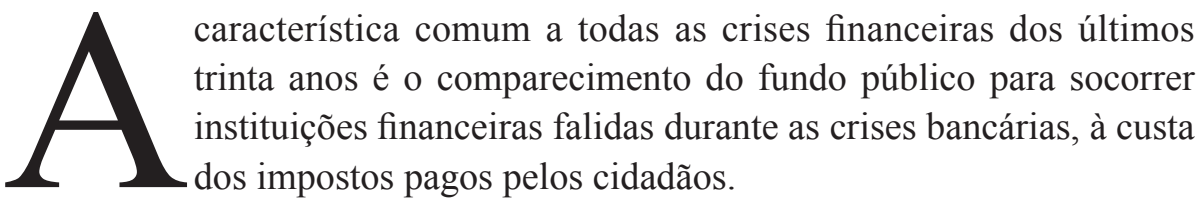

A financeirização da riqueza implica em pressão sobre a política social, especialmente as instituições da seguridade social, pois aí está o nicho dos produtos financeiros. Com isso, as propostas neoliberais incluem a transferência da proteção social do âmbito do Estado para o mercado, a liberalização financeira passa pela privatização dos benefícios da seguridade social.

É no mercado que deve ser comprado o benefício de aposentadoria, o seguro de saúde, que são setores dominantes nos investidores institucionais. Ou seja, benefícios da seguridade social são transformados em mais um "produto" financeiro, alimentando a especulação financeira, tornando as aposentadorias de milhares de trabalhadores refém das crises financeiras internacionais.

Com a financeirização da riqueza, os mercados financeiros passam a disputar cada vez mais recursos do fundo público, pressionando pelo aumento das despesas financeiras do orçamento estatal, o que passa pela remuneração dos títulos públicos emitidos pelas autoridades monetárias e negociados no mercado financeiro, os quais se constituem importante fonte de rendimentos para os investidores institucionais. Com isso, ocorre um aumento da transferência de recursos do orçamento público para o pagamento de juros da dívida pública, que é o combustível alimentador dos rendimentos dos rentistas. Nesse bojo, também se encontram generosos incentivos fiscais e isenção de tributos para o mercado financeiro à custa do fundo público.

Este artigo tem por objetivo discutir a crise do capital a partir do papel exercido pelo fundo público e seus rebatimentos no financiamento da seguridade social no Brasil. Para tanto, o artigo está organizados em quatro seções, além desta introdução. A próxima seção analisa a crise e a instabilidade do capitalismo com o socorro realizado pelo fundo público ao grande capital, além das modificações ocorridas na proteção social sob a égide da financeirização da riqueza. A segunda seção é dedicada ao estudo do fundo público no Brasil, particularmente a regressividade do financiamento tributário e as suas consequências no financiamento da seguridade social. Em seguida apresentam-se os 
rebatimentos da crise do atual do capital sobre o financiamento da seguridade social. Por fim, na última seção são apresentadas algumas propostas para garantir e ampliar os direitos sociais no Brasil.

\section{Crise e instabilidade do capitalismo: 0 papel do fundo público}

Os países capitalistas desenvolvidos passaram por profundas transformações ao longo do século XX, que marcaram avanços na proteção social, particularmente após a Segunda Guerra Mundial, com a consolidação do chamado Estado social. A luta dos trabalhadores por melhores condições de vida e por uma situação mais digna de trabalho construiu a experiência de determinado padrão de proteção social, no período de 1945 a 1975, nos países do centro do capitalismo.

Para tanto, foi decisiva a intervenção do Estado acoplada com as políticas de cunho keynesiano/fordista, destacando-se as modificações redistributivas no orçamento público: pelo lado do financiamento, a implantação de sistemas tributários mais justos tendo como base a cobrança de impostos diretos e progressivos; pelo lado dos gastos, destaca-se, entre as políticas sociais, a edificação da seguridade social, articulando as políticas de seguros sociais, saúde e auxílios assistenciais (Salvador, 2010).

Com isso, ocorre na sociedade também uma disputa por recursos do fundo público no âmbito do orçamento estatal. O orçamento público é um espaço de luta política, onde as diferentes forças da sociedade buscam inserir seus interesses. Na sua dimensão política, o orçamento pode ser visto como uma arena de disputa ou um espaço de luta (ou cooperação) entre os vários interesses que gravitam em torno do sistema político (Inesc, 2006).

O fundo público envolve toda a capacidade de mobilização de recursos que o Estado tem para intervir na economia, além do próprio orçamento, as empresas estatais, a política monetária comandada pelo Banco Central para socorrer as instituições financeiras etc. A expressão mais visível do fundo público é o orçamento estatal. No Brasil, os recursos do orçamento do Estado são expressos na Lei Orçamentária Anual (LOA) aprovada pelo Congresso Nacional.

A Lei Orçamentária Anual (LOA) de 2010 fornece pistas dos valores em disputa no fundo público brasileiro: $\mathrm{R} \$ 1.860 .428 .516 .577,00$. Excluindo o 
refinanciamento da dívida e orçamento de investimento das empresas estatais, os orçamentos fiscal e da seguridade social totalizam R \$1,170 trilhão. No entanto, quase um quarto desse valor (R \$ 271 bilhões) está previsto para o pagamento de juros e amortização da dívida pública, ou seja, destinado à esfera da financeirização da riqueza, beneficiando, conforme Pochmann (2007), apenas 20 mil famílias.

O acelerado crescimento econômico do Brasil, por mais de 50 anos no século XX, não foi capaz de obter resultado da mesma magnitude dos países do capitalismo central, mantendo grande parte de sua população com condições precárias de vida e trabalho. Para Francisco de Oliveira (1990), no caso brasileiro, a intervenção estatal que financiou a reprodução do capital não financiou no mesmo nível a reprodução da força de trabalho, pois teve como padrão a ausência de direitos. A mudança mais importante ocorreu na $\mathrm{CF} / 88$, destacadamente o orçamento social - expresso na política da seguridade social, com financiamento exclusivo.

O fundo público ocupa um papel relevante na articulação das políticas sociais e na sua relação com reprodução do capital. A presença dos fundos públicos na reprodução da força de trabalho e gastos sociais é uma questão estrutural do capitalismo. Para Francisco de Oliveira (1998, p. 19-20), "o fundo público, em suas diversas formas, passou a ser o pressuposto do financiamento da reprodução da força de trabalho, atingindo globalmente toda a população por meio dos gastos sociais".

Existe uma miríade de formas de gastos sociais e de financiamento, incluindo a questão da manutenção e da valorização dos capitais pela via da dívida pública. A formação do capitalismo seria impensável sem o uso de recursos públicos, que, muitas vezes, funcionam como uma "acumulação primitiva". Como se mostra na atual da crise do capitalismo.

De acordo com Behring (2004, p. 164):

Há no argumento de Oliveira um elemento indiscutível: o lugar estrutural do fundo público no capitalismo contemporâneo, como expressão da sua maturidade e imensas contradições. A produção e a realização do valor vão requisitar que o Estado se aproprie de parcela bastante significativa da mais-valia socialmente produzida para assegurar as condições gerais de produção e reprodução; dentro desse processo comparece o desenvolvimento de políticas sociais como lugar relevante de alocação do fundo público, a pender, claro, da correlação de forças políticas e de elementos culturais em cada formação nacional. 
Para compreendermos a crise atual do capitalismo e seus rebatimentos sobre o Brasil é necessário estudar as dinâmicas da financeirização da riqueza e as consequências sobre a proteção social. Nesse sentido, esta seção faz um resgate histórico para compreender a situação da crise atual do capital, e que tudo indica ser uma crise sem precedência na história do capitalismo e distante do seu fim. Pois a Europa está entrando em uma profunda recessão, e esta situação deve durar ao longo dos próximos anos.

Entre o final dos anos 1960 e começo da década de 1970, o desenvolvimento fordista, as políticas keynesianas e o projeto de Estado social, que vigorou nos países centrais, são postos em xeque, e consigo os direitos derivados da relação salarial. A nova fase de acumulação capitalista vai ser capitaneada pela esfera financeira, e no campo ideológico o velho liberalismo se veste com a "nova" roupagem, rebatizado de neoliberalismo.

A crise se manifesta junto com a reação do capital contra o Estado social. A onda de expansão do capitalismo expõe também a contradição do próprio sistema, e o avanço tecnológico com uso intensivo de capital vem acompanhado de economias com a força de trabalho, solapando o pacto dos anos de crescimento com pleno emprego e o arranjo da social-democracia para as políticas sociais.

O baixo retorno dos investimentos produtivos, ou seja, a queda na rentabilidade leva a uma fuga do capital do setor produtivo para a esfera financeira, agindo de forma especulativa. ${ }^{1}$ A especulação financeira vai ganhar novos contornos a partir de meados da década de 1970, com a criação dos novos "produtos" financeiros. A economia americana conviveu nesse período com um processo inflacionário cercado de incertezas financeiras, gerando uma instabilidade internacional das taxas de juros e de câmbio. Nos anos 1960, quando os Estados Unidos passaram a conviver com inflação ascendente e com incertezas financeiras, que levaram à extinção da conversibilidade ouro do dólar ${ }^{2}$ e, por consequên-

1. De acordo com Aglietta (2004), o conceito de especulação foi definido, em 1939, pelo economista Nicholas Kaldor: "a compra (ou venda) de mercadorias tendo em vista uma revenda (ou recompra) em data posterior, onde o móbil de tal ação é antecipação de uma mudança dos preços em vigor, e não uma vantagem resultante de seu uso, ou uma transformação ou transferência de um mercado para outro" (Kaldor, 1987, apud Aglietta, 2004, p. 44). Completa Aglietta (2004, p. 44): “especular, portanto, é antecipar em condições nas quais as variáveis que participam na formação do preço são incertas. É uma atividade orientada para a percepção do futuro".

2. Refere-se ao fim do acordo de Bretton Woods, que permitiu, a partir de julho de 1944, a condução do dólar norte-americano à condição de moeda referencial do sistema financeiro internacional, estabelecen- 
cia, à explosão da instabilidade mundial das taxas de juros e de câmbio, a moeda deixou de ser plenamente estável, mesmo nos países desenvolvidos.

No novo cenário econômico mundial, há uma busca irrestrita de mobilidade global por parte do capital para a qual a flexibilização e as políticas liberalizantes são imperativas. Em verdade, a expansão do capitalismo, na busca de um mercado global, não é novidade na história desse modo de produção.

Uma das novidades no processo de globalização, no século XX, é a acentuação da esfera financeira no processo de acumulação capitalista, em que as alterações em curso trazem maior instabilidade econômica e taxas de crescimento medíocres ou negativas. Por outro lado, são realizadas com o aprofundamento da globalização financeira (Fiori e Tavares, 1993), evidente com a crescente autonomia do capital financeiro relativamente ao setor produtivo industrial e à maior dependência dos investimentos dos fluxos internacionais de capitais, que se tornam mais voláteis e atomizados, trazendo sérias consequências ao "mundo do trabalho" (Mattoso, 1996).

A análise da macroeconomia financeira feita por Aglietta (2004) revela que a partir dos anos 1980 ocorreu uma forte expansão financeira, paralelamente à desaceleração do crescimento econômico nos países desenvolvidos. $\mathrm{O}$ novo ambiente financeiro foi propício para a acumulação patrimonial das famílias mais ricas.

Para Aglietta (2004, p. 25; grifos nossos):

A desregulamentação das finanças abriu novas perspectivas para a poupança, que saiu de seus refúgios tradicionais, nos bancos e nas cadernetas de poupança, rumo a mercados de títulos e a aquisições imobiliárias. Esse redirecionamento foi canalizado pelos investidores institucionais (companhias de seguros e fundos de pensão) que foram forçados pela concorrência a realizar administrações mais dinâmicas das carteiras que lhes eram confiadas. Ele também foi acelerado por novos intermediários do mercado, fundos de participação e negociadores de títulos de todos os tipos. A atração das famílias foi garantida pelas esperanças de

\footnotetext{
do a hegemonia norte-americana no sistema monetário, pois nos EUA estava a maior parte do ouro que lastreava o dólar. Em 15 de agosto de 1971, o presidente dos Estados Unidos, Richard Nixon, anunciou ao mundo o fim da conversibilidade do dólar em ouro, acabando com o acordo de Bretton Woods, rompendo com o sistema de câmbio fixo, que regulava as economias dos países centrais e, portanto, os fluxos financeiros e de comércio que funcionavam desde o segundo pós-guerra.
} 
ganhos de capital suscitados pelos mercados abertos, desregulamentados e vitaminados por incentivos fiscais.

As transformações que vêm ocorrendo no sistema financeiro internacional têm levado os bancos, a partir dos anos 1980, a adotar estratégias que possam garantir formas de acumulação de capital num quadro de maior concorrência no setor bancário. Nesse contexto nascem os novos instrumentos financeiros, como a securitização das dívidas e os derivativos. Esses produtos ganham agilidade com os avanços tecnológicos em informática e telecomunicações no sistema financeiro.

O desenvolvimento desses mercados especulativos permitiu um enriquecimento privado, sem encorajar o investimento produtivo. Aglietta (2004, p. 27) destaca que nos anos 1980 ocorre uma "orientação da poupança rumo aos investidores institucionais, graças ao desenvolvimento de regimes de aposentadoria por capitalização em numerosos países, estimulado pelas perspectivas do envelhecimento demográfico".

Por outro lado, a vulnerabilidade do sistema financeiro pode levar à existência do risco sistêmico, ocasionando a reestruturação global das instituições financeiras, dada a natureza especulativa da atuação destas, dos preços dos ativos financeiros extremamente flexíveis e de política monetária restrita à taxa de juros. Com isso, o "efeito dominó" mundial é de risco permanente em tempos de globalização financeira.

Historicamente, os recursos financeiros centralizados pela dívida sempre foram cativos dos mercados financeiros. Com a nova etapa da acumulação financeira, os dividendos tornam-se também um mecanismo importante de transferência de riqueza e de acumulação. A pressão dos mercados sobre os grupos industriais impõe novas normas de rentabilidade e exigências de redução de custos salariais, aumento de produtividade e flexibilidade nas relações de trabalho. O corolário da liberalização financeira é a ressurreição de ciclos econômicos, que são intensamente influenciados pelos preços dos ativos financeiros.

A partir da década de 1980, a economia norte-americana passa a conviver com crises bancárias repetidas, além de um craque da Bolsa (outubro, 1987) e de crise imobiliária ao final do século XX, e que vem a se repetir em 2008. Com crises financeiras recorrentes, a principal função dos bancos torna-se impossível, pois o efeito delas é exatamente a desorganização da intermediação financeira. Diante disso, os bancos não têm mais informações sobre seus devedores, o que 
leva ao estrangulamento do crédito, o qual tem rebatimento sobre toda a economia, acarretando, por consequência, a depressão econômica (Aglietta, 2004).

$\mathrm{Na}$ última década do século XX, a liberalização financeira chegou aos países em desenvolvimento. Os governos das grandes potências que se debatiam com as sequelas da crise imobiliária (1990-91) e as grandes instituições financeiras que buscavam novos terrenos de expansão elaboraram uma doutrina batizada de "Consenso de Washington". Por intermédio do FMI, tratava-se de persuadir os governos dos países em desenvolvimento e dos países desorientados pelo desabamento do comunismo a se engajar rapidamente na liberalização financeira para um ajuste estrutural rumo à economia de mercado. Os países que aderiram aos novos rumos da globalização financeira ficaram conhecidos como "mercados emergentes". Sendo alvo para os grandes intermediários financeiros internacionais de uma convenção financeira otimista, atraíram uma avalanche de capitais especulativos com regras tributárias favorecidas.

O mundo das finanças globalizadas tem sido marcado por uma sucessão de crises financeiras. A fragilidade sistêmica das crises, conforme Chesnais (2005), está no volume elevado de créditos sobre a produção futura que os detentores de ativos financeiros consideram pretender, assim como na busca de resultados das aplicações financeiras dos administradores de fundos de pensão. Em contexto de baixo crescimento econômico comparativamente aos capitais que buscam se valorizar nos mercados financeiros, as crises financeiras decorrentes da especulação e da instabilidade sistêmica são inevitáveis.

A liberalização financeira tem sido marcada por sucessivas crises. Na realidade como lembra Lordon (2007, p. 1):

Desde que ela se impôs, tem sido difícil passar mais de três anos seguidos sem um incidente de envergadura. Quase todos poderiam figurar nos livros de história econômica: 1987, quebra dos mercados de ações; 1990, quebra dos junk bonds ("títulos podres") e crise das savings and loans (instituições financeiras de poupança e empréstimos) norte-americanas; 1994, crise de debêntures norte-americanos; 1997, primeira fase da crise financeira internacional (Tailândia, Coreia, Hong Kong); 1998, segunda fase (Rússia, Brasil); 2001-2003, estouro da bolha da internet. ${ }^{3}$

3. Refere-se ao estouro da bolha especulativa das empresas "pontocom". Conforme Duménil e Lévy (2008): “Após as recessões de 1982 e 1990, a atividade foi efetivamente sustentada pelo impulso miraculo- 
As crises financeiras nos anos 1990, nos chamados países emergentes (Rússia, México, Argentina, Brasil, Tailândia, Indonésia e Filipinas), são resultados diretos da liberalização e da desregulamentação comercial e privatização dos sistemas produtivos desses países. Para Chesnais (2005), os investidores institucionais incorporaram esses países à mundialização financeira, mas também perceberam a submissão completa às políticas neoliberais para a captação dos fluxos de renda.

Em 2008, o mundo é novamente abalado por uma crise financeira de proporções ainda não dimensionadas, mas para muitos comparada ao que o capitalismo vivenciou nos anos 1930. O cataclismo econômico tem como epicentro os Estados Unidos. ${ }^{4}$ A crise teve origem nos empréstimos hipotecários norte-americanos, se arrastando inicialmente para os bancos de investimentos, as seguradoras e os mercados financeiros, enfim, a crise se espalhou rápido pela economia dos Estados Unidos e atinge, atualmente, a Europa e o Japão. Os desdobramentos são para a economia global, que entra em recessão.

Lordon (2007) destaca o fato de a bolha especulativa nos mercados financeiros ser muito próxima à fraude, que requer a atração e a entrada constante de novos investidores para manter o mercado em alta e a ilusão de que ganharão sempre.

O segredo é a adesão especulativa por meio de produtos financeiros de alta rentabilidade que atraem aplicadores cada vez mais comuns e numerosos, porém cada vez menos esclarecidos. Para prolongar o crescimento do mercado imobiliário norte-americano, se possível eternamente, era necessário que as famílias fossem levadas a procurar o mercado de empréstimos hipotecários, seduzidas pelo sonho norte-americano da propriedade.

A criatividade do sistema fez com que surgissem as hipotecas de segunda linha (subprime mortgages) com beneficiários de duvidosa capacidade de pa-

\footnotetext{
so das novas tecnologias, ditas 'da informação'. Lentamente no começo, mas de modo particularmente tenaz, a onda agigantou-se na segunda metade da década de 1990: quatro anos de boom, durante os quais os valores tecnológicos foram propelidos a alturas sem precedentes: a bolsa Nasdaq, que negociava ações de 1.053 empresas em janeiro de 1996, passou a abrigar $5.132 \mathrm{em}$ março de 2000. O capital estrangeiro afluiu precipitadamente para aproveitar a inesperada vantagem. Mas ao boom seguiu-se o crack estrondoso: em outubro de 2002, o número de empresas com ações na Nasdaq havia despencado para 1.114".

4. Uma análise jornalística crítica da crise financeira de 2008 pode ser lida no Le Monde Diplomatique (edição brasileira) escrita pelo jornalista Antonio Martins com o título "Para compreender a crise financeira", em 7/10/2008. Disponível em: <http://diplo.uol.com.br/2008-10,a2623>.
} 
gamento. Mesmo que existam dificuldades de honrar os empréstimos, os tomadores e os emprestadores avaliam que o imóvel poderá ser vendido com valorização para uns e comissão para outros, honrando assim o pagamento da hipoteca.

A criatividade do mercado financeiro para se desfazer do risco aumentou consideravelmente com a liberalização financeira e a falta de regulamentação do mercado. Os bancos ficam com os lucros e socializam os possíveis prejuízos. Assim, os novos produtos financeiros, como os derivativos - absolutamente sem regulação e controle do Estado - , levaram os bancos dos EUA a se livrar do problema de créditos de duvidosa liquidação (empréstimos imobiliários), que ficam registrados nos balanços, por meio da securitização das dívidas.

Os investidores institucionais, entre eles os fundos de pensão que devem honrar o pagamento de aposentadorias, são alguns dos clientes desses produtos, que, apesar do alto risco, oferecem elevado retorno, obviamente quando tudo vai bem. Os investidores fazem isso por meio de fundos de investimentos aplicados em diversos mercados, visando diminuir riscos e reduzir eventuais prejuízos ao mesmo tempo (hedge funds).

Mas na crise o contágio será global. O pacote dos produtos derivados do mercado imobiliário prometendo elevado retorno foi vendido no mercado financeiro globalizado, encontrando-se nas mãos de inúmeros portadores. Porém o início da história está no mundo real, ou seja, nos créditos imobiliários que devem ser honrados.

A crise financeira se instala primeiro nos bancos; a partir disso, há uma grande perda e o colapso tem seu início. Com a globalização financeira, a situação não se limita às fronteiras norte-americanas, uma vez que a securitização dos títulos gerou créditos espalhados em vários mercados financeiros no mundo. Quando a crise se instala, todo o discurso e a defesa da eficiência do mercado, da privatização, da desregulamentação se "desmancham no ar", chamem o Estado, ou melhor, o fundo público para socializar os prejuízos. Rapidamente o discurso da eficiência dos mercados parece ter sido esquecido.

Uma amostra que a crise econômica global ainda não se esfacelou pode ser encontrada nas dificuldades expostas recentemente pelos países europeus, que compõem o chamado PIIGS: Portugal, Irlanda, Itália, Grécia e Espanha. Esses países europeus apresentam elevada dívida pública, e há dúvidas no mercado financeiro internacional da capacidade de honrar o pagamento. A Itá- 
lia e a Grécia têm dívidas que superam o tamanho do Produto Interno Bruto (PIB). A moeda da União Europeia, euro, vem sofrendo forte desvalorização frente ao dólar, e diversos analistas veem risco para o sistema bancário da Europa. É importante observar que a moeda é unificada, mas os títulos públicos são nacionais.

As regras da União Europeia definidas pelo Tratado de Maastricht impõem o teto de 3\% sobre o déficit público. ${ }^{5}$ Esse limite não vem sendo respeitado por alguns países, como a Alemanha, que tem déficit acima 6\% do PIB. Contudo, os países do PIIGS apresentam déficit entre 10\% e 12,7\% do PIB — como é o caso da Grécia - , e devido à menor robustez dessas economias existe o risco de default.

A situação se agravou a partir da crise financeira que fez elevar ainda mais o déficit público no Sul da Europa, pois, na tentativa de tirar a economia da recessão, esses países aumentaram seus gastos públicos para socorrer o capital, principalmente os bancos. Hoje, com o aperto do crédito, o endividamento da economia e o "descontrole" fiscal aliado à baixa competitividade da região, coloca-se em risco o prolongamento da crise econômica mundial. O paradoxo é que a "receita" neoliberal capitaneada pelo FMI, que aprofundou a crise atual do capital, ressurge das "cinzas" e aparece nas políticas econômicas adotadas há pouco pelos países europeus, notadamente o ajuste fiscal e o corte nos gastos sociais. Está em curso uma nova onda conservadora no cenário mundial.

Hoje é importante notar que a liberalidade financeira, os instrumentos de curto prazo (como novos produtos financeiros) de sustentação dos lucros das empresas e de proteção dos portfólios do setor bancário privado, as políticas de geração de déficit e a criação da nova dívida pública trazem consequências danosas e expectativas nada animadoras para o futuro desses países.

A tendência é de um brutal corte de direitos e de conquistas sociais, sobretudo no campo da seguridade social. O que está em jogo é a avaliação que o mercado fará, particularmente o capital portador de juros, acerca da direção da política fiscal, do endividamento público e da redução do déficit externo. O corolário poderá ser o arrocho fiscal com seus efeitos colaterais: recessão, redução do salário e do emprego nos setores público e privado.

5. Note-se que, por esse critério, o Brasil poderia participar da Zona do Euro, pois vem praticando, nos últimos anos, um superávit primário acima de $3 \%$ do PIB. 
O capital portador de juros está localizado no centro das relações econômicas e sociais da atualidade e da atual crise financeira em curso no capitalismo contemporâneo. Os juros da dívida pública pagos pelo fundo público ou a conhecida despesa "serviço da dívida" do orçamento estatal (juros e amortização) são alimentadores do capital portador de juros por meio dos chamados "investidores institucionais" que englobam os fundos de pensão, fundos coletivos de aplicação, sociedades de seguros, bancos que administram sociedades de investimentos.

Tudo isso agrava-se diante da crise dos países europeus, que, oprimidos pela dívida, poderão minar a economia do continente como um todo, situação que, persistirá por anos. Esses países deverão fazer pesados pagamentos de juros para honrar as suas dívidas, limitando os gastos em outras áreas e a expansão de despesas orçamentárias com políticas públicas que efetivem direitos, que poderiam ajudar a impulsionar suas economias.

Para Pochmann (2004), nos países capitalistas desenvolvidos no segundo pós-guerra privilegiou-se a redistribuição da renda gerada por meio dos fundos públicos, com tributação sobre os mais ricos e transferências dos recursos dos fundos para os mais pobres. O Estado social não tratou apenas de disponibilizar serviços sociais e garantir renda aos pobres, mas tratou principalmente de retirar das forças de mercado o monopólio da expansão econômica e da gestão sobre a força de trabalho.

Pela primeira vez, os ricos passaram a pagar impostos, especialmente com o mecanismo da progressividade sobre a renda e patrimônio, assim como a população pauperizada passou a ser beneficiada tanto pelo acesso aos serviços públicos básicos (educação, saúde, transporte e moradia) como pelos programas de garantia de renda para estudo (bolsa de estudos), aposentadoria (inatividade por velhice), situação de invalidez ocupacional (pensão para deficientes físicos e mentais e doenças profissionais) e condição de desemprego (seguro-desemprego).

Em resumo, consolidou-se uma nova estrutura secundária (fundo público) de redistribuição da renda, que veio a se sobrepor à já existente estrutura distributiva primária constituída pela própria dinâmica capitalista. Enquanto os ricos passaram a ser tributados consideravelmente (impostos sobre a renda, patrimônio e herança), foi possível formar fundos públicos capazes de financiar a transferência de renda para a população de menor rendimento, permitindo reduzir a pobreza, o desemprego e a desigualdade social no centro do capitalismo mundial (Pochmann, 2004). 
Contudo este não é o caso do Brasil. O fundo público no nosso país historicamente favoreceu a acumulação de capital e apresenta características regressivas, tanto no lado do financiamento tributário, quanto na destinação dos recursos. Em uma única frase é possível definir as características do orçamento público no Brasil: financiado pelos mais pobres e trabalhadores e apropriados pelos ricos.

\section{Fundo público, tributação e seguridade social no Brasil}

Historicamente, o financiamento tributário no Brasil é regressivo, ou seja, feito por tributos indiretos que incidem sobre o consumo, sendo que a tributação direta fica limitada à tributação sobre os salários. Essa situação piorou de 1995 para os dias atuais, devido às alterações realizadas na legislação tributária infraconstitucional, que modificaram a reforma tributária realizada na Constituição Federal (CF) de 1988.

A nossa pesquisa (Salvador, 2010) revela que a CF determina uma série de princípios norteadores da política tributária. Assim, por exemplo, o imposto de renda deverá obedecer, entre outros critérios, ao da progressividade. Além disso, o Estado deve respeitar o princípio da capacidade contributiva $(\mathrm{CF}$, art. 145 , III, $\S 1^{\circ}$ ), e os tributos sobre bens e serviços não devem ser cumulativos. A Constituição, em 1988, estabeleceu um conjunto de princípios tributários (eles ainda estão lá escritos) que constituíam uma base importante para edificação de um sistema tributário baseado na justiça fiscal e social. A começar pela solidariedade que está subjacente a todos os princípios tributários: a isonomia, a universalidade, a capacidade contributiva, a essencialidade. A tributação deve ser, preferencialmente, direta, de caráter pessoal e progressiva.

A CF estabelece ainda que os contribuintes e os consumidores sejam esclarecidos acerca dos impostos que incidem sobre mercadorias e serviços. Até hoje, esse preceito não foi regulamentado e não está sendo cumprido. O parágrafo $1^{\circ}$ do art. 145 estabelece que os impostos terão caráter pessoal e serão graduados segundo a capacidade econômica do contribuinte, facultado à administração tributária, especialmente para conferir efetividade a esses objetivos, identificar, respeitados os direitos individuais e nos termos da lei, o patrimônio, os rendimentos e as atividades econômicas do contribuinte. No art. 150 fica 
assegurada a isonomia tributária ao proibir o tratamento desigual entre contribuintes que se encontrem em situação equivalente.

Ao longo do governo FHC foi sendo alterada, paulatinamente, a legislação infraconstitucional, solapando ou tornando nulos os princípios básicos da reforma tributária realizada na Constituição de 1988, agravando as distorções e, sobretudo, aprofundando a regressividade do sistema tributário brasileiro. As modificações realizadas nos anos neoliberais no Brasil constituem verdadeira contrarreforma tributária, conduzida de forma sorrateira.

As modificações ocorreram nas leis ordinárias e nos regulamentos tributários, que transferiram para a renda do trabalho e para a população mais pobre o ônus tributário, alterando o perfil da arrecadação. Hickmann (2003) observa que as mudanças foram no sentido de viabilizar o processo de mundialização do capital financeiro, sob a batuta do Fundo Monetário Internacional (FMI) e facilitando o livre fluxo de recursos financeiros, e, com isso, permitir a realização de sucessivos superávits primários de forma a cumprir o ajuste fiscal acertado com o organismo multilateral.

A contrarreforma tributária sorrateira iniciada no governo FHC e continuada no governo Lula destruiu os artigos constitucionais dos princípios tributários, via mudanças na legislação infraconstitucional. Solapou o artigo 150, pois os lucros e dividendos recebidos pelos sócios capitalistas estão isentos de imposto de renda desde 1996. A título de exemplo, das 23,5 milhões de declarações de ajuste de imposto de renda do ano-base de 2006 (exercício de 2007), apenas 5.292 contribuintes apresentaram rendimentos tributáveis acima de R \$ 1 milhão. ${ }^{6}$ Paradoxalmente, o número de milionários no país não para de crescer. Conforme revelou o levantamento da The Boston Consulting Group (BCG), o Brasil tinha, em 2008, 220 mil milionários, uma expansão de $15,7 \%$ em relação ao ano anterior (Wiziack, 2008). A fortuna desses milionários está estimada em aproximadamente US\$ 1,2 trilhão, o que equivale a praticamente metade do PIB brasileiro. Para o BCG, milionários são aqueles que têm mais de US\$ 1 milhão aplicado no mercado financeiro. Os juros têm tributação exclusiva e bem menor que os trabalhadores assalariados.

No governo Lula foi editada a Medida Provisória (MP) n. 281 (15/2/2006), reduzindo a zero as alíquotas de IR e da (extinta) CPMF para "investidores"

6. Informações fornecidas pela SRFB ao Observatório de Equidade do Conselho de Desenvolvimento Econômico e Social (Brasil, 2009). 
estrangeiros no Brasil. As operações beneficiadas pela MP são cotas de fundos de investimentos exclusivos para investidores não residentes que possuam no mínimo 98\% de títulos públicos federais. Novamente, os grandes beneficiados pela benevolência tributária do Estado brasileiro são os bancos. Após a MP n. 281, vem crescendo o interesse dos bancos estrangeiros com filiais no Brasil em emitir bônus indexados em reais no exterior. Eles emitem títulos em reais fora do país pagando juros abaixo do Depósito Interfinanceiro (DI) e depois ingressam com esses recursos como investidores estrangeiros no Brasil, comprando títulos públicos que pagam DI. Assim, ganham a diferença realizando uma operação de arbitragem (Lucchesi, 2006). Essa é mais uma modificação da legislação que fere a isonomia tributária entre as diferentes espécies de renda, conforme a Constituição Federal. A legislação atual não submete à tabela progressiva do IR os rendimentos de capital, que são tributados com alíquotas inferiores aos demais rendimentos (Hickmann, 2002).

A Lei n. 11.033, de 21/12/2004, promoveu significativas alterações no tratamento tributário das aplicações financeiras, favorecendo os aplicadores do mercado financeiro e da Bolsa de Valores. Com isso, a alíquota do IR sobre os ganhos líquidos auferidos em operações realizadas em Bolsas de Valores, de Mercadorias, de Futuros e assemelhadas, foi reduzida de 20\% para 15\%. Além disso, estão isentos do IR os ganhos líquidos auferidos por pessoa física em operações no mercado à vista de ações, cujo valor das alienações realizadas em cada mês seja igual ou inferior a R \$ 20 mil para o conjunto de ações.

Em linhas gerais, as principais tendências que marcam as modificações no financiamento tributário no Brasil após 1994 são: a) aumento da regressividade da carga tributária com a maior incidência de tributos sobre o consumo de bens e serviços; b) apesar da baixa participação da renda dos salários sobre o total da renda nacional da economia, a tributação direta no Brasil tem se limitado e incidido cada vez mais sobre a renda dos assalariados, usando como mecanismo a não correção integral pela inflação da tabela do IR; c) tratamento diferenciado da tributação das rendas no país, violando o princípio da isonomia tributária ao tratar com critérios diferenciados a renda do capital (lucros, dividendos e juros) e do trabalho, pois há concentração cada vez maior de imposto sobre a renda dos trabalhadores assalariados; e d) maior beneficiamento do sistema financeiro pelas modificações ocorridas nas legislações tributárias do período recente, o que faz com que, assim, seja proporcionalmente menos tributado que os trabalhadores e outros setores da economia (Salvador, 2010). 
Estudo realizado com base na Pesquisa de Orçamento Familiar (POF) do IBGE, de 1996, revela que, no Brasil, quem ganha até dois salários mínimos gasta $26 \%$ de sua renda no pagamento de tributos indiretos, enquanto o peso da carga tributária para as famílias com renda superior a trinta salários mínimos corresponde apenas a 7\% (Vianna et al., 2001). Com base nos dados da Pesquisa de Orçamento Familiar (POF) do IBGE de 2002-03, estima-se que as famílias com renda de até dois salários mínimos arcam como uma carga tributária indireta de $46 \%$ da renda familiar, enquanto aquelas com renda superior a 30 salários-mínimos gastam $16 \%$ da renda em tributos indiretos (Zockun, 2005). O resultado é uma carga tributária regressiva, o que significa que o Estado brasileiro é financiado, em grade parte, pelas classes de menor poder aquisitivo e pelos trabalhadores, com a população de baixa renda suportando uma elevada tributação indireta. Pochmann (2008) também destaca, com base nos dados da POF do IBGE 2002-03, que o décimo mais pobre da população sofre uma carga total equivalente a $32,8 \%$ da sua renda, enquanto o décimo mais rico, apenas $22,7 \%$.

Essa estrutura regressiva do sistema tributário repercute no financiamento da seguridade social. Um olhar sobre o financiamento seguridade social, no período de 2000 a 2007, identificando as bases econômicas de incidência tributária (renda, consumo e patrimônio), que compuseram o custeio das três políticas da seguridade, revela uma estrutura tributária regressiva, confirmando as características presentes no sistema tributário brasileiro. O resultado apresentado, com base na média anual das fontes de financiamento da seguridade social, no período de 2000 a 2007, em valores constantes, revela que os tributos diretos responderam por $30,87 \%$, dos quais somente $6,88 \%$ referem-se à tributação direta da renda do capital. Isto significa que os próprios beneficiários da seguridade social pagam direta ou indiretamente seus beneficios (Salvador, 2010).

No lado dos gastos, a prioridade do fundo público tem sido o pagamento de juros e a amortização. As despesas financeiras que representavam 26,86\% dos orçamentos da seguridade social e fiscal em 2004, sobem para $30,77 \%$ em 2007 (Tabela 1). Os valores pagos com juros e amortização da dívida nos quatro anos de execução do PPA 2004-07 são duas vezes superiores ao montante do gasto da União com assistência social, saúde, trabalho, educação, cultura, direitos da cidadania, habitação, saneamento, gestão ambiental, organização agrária, desportos e lazer. 
TABELA 1

Despesas com a Dívida, 2004 a 2007 — R \$ milhões

\begin{tabular}{|c|c|c|c|c|}
\hline Ano & $\begin{array}{c}\text { Juros e encargos } \\
\text { (a) }\end{array}$ & $\begin{array}{c}\text { Amortizações } \\
\text { (b) }\end{array}$ & $\begin{array}{l}\text { Despesas financeiras } \\
\text { (c) }=(\text { a })+(\text { b) }\end{array}$ & Refinanciamento \\
\hline 2004 & $74.373,39$ & $71.677,57$ & $146.050,96$ & $364.418,01$ \\
\hline 2005 & $89.839,64$ & $49.274,21$ & $139.113,85$ & $495.579,15$ \\
\hline 2006 & $151.151,88$ & $120.929,46$ & $272.081,34$ & $376.832,92$ \\
\hline 2007 & $140.311,78$ & $97.093,32$ & $237.405,11$ & $374.783,32$ \\
\hline Total & $455.676,70$ & $338.974,55$ & $794.651,25$ & - \\
\hline \multicolumn{4}{|c|}{ Participação no Orçamento em \% } & \\
\hline 2004 & $13,68 \%$ & $13,18 \%$ & $26,86 \%$ & \\
\hline 2005 & $14,80 \%$ & $8,12 \%$ & $22,92 \%$ & \\
\hline 2006 & $18,73 \%$ & $14,99 \%$ & $33,72 \%$ & \\
\hline 2007 & $18,18 \%$ & $12,58 \%$ & $30,77 \%$ & \\
\hline Média & $16,35 \%$ & $12,22 \%$ & $28,57 \%$ & \\
\hline \multicolumn{4}{|c|}{ Em valores deflacionados pelo IGP-DI } & \\
\hline Ano & $\begin{array}{c}\text { Juros e encargos } \\
\text { (a) }\end{array}$ & $\begin{array}{c}\text { Amortizações } \\
\text { (b) }\end{array}$ & $\begin{array}{l}\text { Despesas financeiras } \\
\qquad(c)=(a)+(b)\end{array}$ & \\
\hline 2004 & $92.164,11$ & $88.823,43$ & $180.987,54$ & \\
\hline 2005 & $101.762,45$ & $55.813,49$ & $157.575,93$ & \\
\hline 2006 & $161.572,94$ & $129.266,85$ & $290.839,79$ & \\
\hline 2007 & $147.442,01$ & $102.027,31$ & $249.469,33$ & \\
\hline Total & $502.941,50$ & $375.931,08$ & $878.872,59$ & \\
\hline Média & $125.735,38$ & $93.982,77$ & $219.718,15$ & \\
\hline \multicolumn{4}{|c|}{ Em \% do PIB } & \\
\hline Ano & $\begin{array}{c}\text { Juros e encargos } \\
\text { (a) }\end{array}$ & $\begin{array}{c}\text { Amortizações } \\
\text { (b) }\end{array}$ & $\begin{array}{l}\text { Despesas financeiras } \\
\qquad(c)=(a)+(b)\end{array}$ & \\
\hline 2006 & $3,83 \%$ & $3,69 \%$ & $7,52 \%$ & \\
\hline 2005 & $4,18 \%$ & $2,29 \%$ & $6,48 \%$ & \\
\hline 2006 & $6,48 \%$ & $5,18 \%$ & $11,66 \%$ & \\
\hline 2007 & $5,48 \%$ & $3,79 \%$ & $9,28 \%$ & \\
\hline
\end{tabular}

Fonte: Siafi/SIGA Brasil. 
Mandel (1990) argumenta que no capitalismo tardio há uma tendência inevitável de que o Estado incorpore um número crescente de setores produtivos e reprodutivos às condições gerais de produção que financia. Sem essa socialização dos custos, esses setores não seriam nem mesmo remotamente capazes de satisfazer as necessidades do processo capitalista de trabalho. Com isso, ocorre o uso crescente do orçamento do Estado para o financiamento de pesquisas e dos custos do desenvolvimento, e as despesas estatais são destinadas a financiar ou subsidiar grandes projetos industriais.

O fundo público não pode ser considerado o antivalor, como afirma Chico de Oliveira. O fundo público está presente na reprodução do capital (Salvador, 2010):

1) Como fonte importante para a realização do investimento capitalista. No capitalismo contemporâneo, o fundo público comparece por meio de subsídios, de desonerações tributárias, por incentivos fiscais, por redução da base tributária da renda do capital como base de financiamento integral ou parcial dos meios de produção, que viabilizam, como visto anteriormente, a reprodução do capital.

2) Como fonte que viabiliza a reprodução da força de trabalho, por meio de salários indiretos, reduzindo o custo do capitalista na sua aquisição. Além disso, é a força de trabalho a responsável direta, no capitalismo, pela criação do valor.

3) Por meio das funções indiretas do Estado, que no capitalismo atual garante vultosos recursos do orçamento para investimentos em meios de transporte e infraestrutura, nos gastos com investigação e pesquisa, além dos subsídios e renúncias fiscais para as empresas.

4) No capitalismo contemporâneo, o fundo público é responsável por uma transferência de recursos sob a forma de juros e amortização da dívida pública para o capital financeiro, em especial para as classes dos rentistas.

Portanto, o fundo público participa indiretamente da reprodução geral do capital, seja por meio de subsídios, negociação de títulos e garantias de condições de financiamento dos investimentos dos capitalistas, seja como elemento presente e importante na reprodução da força de trabalho, única fonte de criação de valor na sociedade capitalista. 


\section{Os rebatimentos da crise no financiamento da seguridade social}

Em um mundo capitalista dominado pela globalização financeira, é importante analisar os desdobramentos dessa nova face da crise para o Brasil. A moeda brasileira, que tem seguido a variação dos preços das commodities, tende a se depreciar enquanto persistirem as incertezas na economia global. $\mathrm{O}$ movimento esperado é que os investidores financeiros ou, melhor dizendo, os especuladores financeiros retirem recursos dos países emergentes para se refugiarem no dólar e em títulos do governo americano, dificultando o financiamento do balanço de pagamentos do Brasil.

Esse movimento já é sentido no Brasil, cuja apreciação da moeda norte-americana é superior a $8 \%$ neste ano. Ou seja, a situação econômica de alguns países europeus cria pânico nos mercados e encarece o dólar no Brasil. Caso ocorra uma desvalorização ainda maior do real, poderá haver alguma consequência desagradável para a economia brasileira, decorrente do encarecimento do crédito externo, da pressão inflacionária e das dificuldades a ser enfrentadas pelos produtos brasileiros que são exportados para a Europa. Convém atentar para o desdobramento sobre os bancos de capital estrangeiro com matriz nos países europeus e agências no Brasil, uma vez que o sistema financeiro se internacionalizou de forma considerável nos últimos anos.

O Brasil não foi poupado da crise financeira internacional, contudo, foi um dos últimos atingidos e um dos primeiros a sair dela. Isto por diversos motivos, entre eles menor endividamento comparado com as economias mais ricas do planeta e por ser grande produtor de commodities, que cresceram consideravelmente no segundo semestre de 2009, puxada pelas importações da China (hoje o maior parceiro comercial do Brasil).

Além disso, o volume de operações de crédito fechou 2009 com novo recorde, após crescer por dez meses consecutivos. De acordo com dados divulgados pelo Banco Central, o estoque total de dinheiro emprestado cresceu 1,6\% em dezembro em relação ao mês anterior e chegou ao valor recorde de $\mathrm{R} \$ 1,41$ trilhão. No ano, o crescimento foi de 14,9\%. Contudo, essa situação poderá indicar problemas futuros de endividamento das famílias.

Associada à expansão do crédito destaca-se o potencial do consumo interno proporcionado pelas políticas sociais no campo da seguridade social: previdência e assistência social. Essas políticas, que têm sido alvo permanente de 
ataques do neoliberalismo, transferem renda para mais de 39 milhões de pessoas. Em 2009, foram pagos 15,5 milhões de benefícios no Regime Geral de Previdência Social (RGPS) aos trabalhadores urbanos; 7,9 milhões aos trabalhadores rurais; 3,4 benefícios assistenciais (BPC e RMV); e, 12,3 milhões de famílias receberam o benefício do Programa Bolsa Família (PBF). Esses benefícios foram responsáveis pela injeção de $\mathrm{R} \$ 257,2$ bilhões na economia em 2009, o que garantiu a continuidade do consumo, independentemente da renda advinda do trabalho, e são importantes conquistas da cidadania brasileira na Constituição de $1988 .^{7}$

No âmbito das políticas monetárias e fiscais, o governo brasileiro agiu rápido no socorro ao grande capital, especialmente o financeiro. Considerando as medidas de combate à crise, que não têm impacto direto no caixa do governo (orçamento público), o montante de recursos que foi despendido alcançou R \$ 475 bilhões. Nesse valor estão, sobretudo, as medidas adotadas no campo da política monetária, destacadamente as mudanças nas regras do depósito compulsório, leilões com dólar e a linha de troca de moeda com o Federal Reserve (FED), que somaram R $\$ 284$ bilhões. Com isso, o Banco Central socorreu os bancos mais uma vez.

A flexibilização nas regras dos depósitos compulsórios foi também uma oportunidade para que algumas instituições financeiras pudessem elevar os recursos que têm em caixa com a venda de ativos para os maiores bancos. De forma que o fundo público no Brasil atuou no âmbito das políticas monetárias no sentido de liberar recursos para as instituições financeiras, sem quaisquer contrapartidas de manutenção ou ampliação de postos de trabalhos e dos direitos sociais. A rapidez e a agilidade do fundo público brasileiro usadas para socorrer o mercado financeiro são mais uma amostra da influência dos bancos no domínio da agenda econômica do nosso país.

No campo política fiscal, as medidas adotadas pelo Brasil foram bem mais modestas. A Organização Internacional do Trabalho (OIT) divulgou, em março de 2009, que o Brasil foi o país que teve em 2008 o menor gasto relativo, entre os aqueles que integram o G-20, em medidas para reduzir o impacto da crise financeira global. De acordo com a OIT, o Brasil gastou o equivalente a $0,2 \%$

7. Dados extraídos dos dados do Sistema Integrado da Administração Financeira (Siafi), disponibilizados pelo sistema Siga (www.senado.gov.br). 
do PIB em incentivos fiscais, ficando com o pior desempenho entre os 32 países que também anunciaram recursos. A Organização conclui, com base nas medidas contra a crise anunciadas por 32 países, que o montante destinado a pacotes de estímulo chegou a US $\$ 1,19$ trilhão, mas que apenas $1,8 \%$ do total foi investido em ações de proteção social e somente $9,2 \%$ das despesas foram destinadas a promover o emprego. Portanto, o conservadorismo fiscal no Brasil é bem mais rígido que alhures.

Mesmo com a crise de 2009, diante da qual que se esperava uma atitude mais ousada do governo brasileiro para a expansão de gastos com direitos que protegessem os cidadãos da instabilidade econômica, o governo optou por fazer um superávit primário efetivo do setor público de 1,93\% do PIB, ou seja, já descontando o resultado dos investimentos do Programa de Aceleração do Crescimento (PAC).

Esse resultado implica forte restrição na ampliação das despesas orçamentárias destinadas a garantir direitos da seguridade social. Esse resultado financeiro superavitário foi também garantido pelas medidas extraordinárias tomadas pelo governo federal no fim de 2009 para elevar as receitas fiscais, como o recolhimento de depósitos judiciais e a antecipação de dividendos da Eletrobrás.

A pressão pelo ajuste nas contas públicas deverá recair sobre as despesas sociais, particularmente do orçamento da seguridade social. Aliás, essa situação fiscal deverá ser tema dominante na pauta econômica da eleição presidencial deste ano, com setores conservadores defendendo a realização de déficit nominal zero para o próximo governo. Para este ano, as declarações do secretário do Tesouro Nacional, Arno Augustin, é que o governo vai cumprir a "meta cheia" do superávit primário de 3,3\% do PIB em 2010, sem abater investimentos do PAC como em 2009. E de acordo com o secretário deve ocorrer queda nominal das despesas públicas, após a elevação de $15 \%$ no ano passado.

Em relação às despesas públicas, é importante dizer que se constitui um mito a afirmação que há um descontrole nas despesas com pessoal, pois os gastos públicos com ativos, aposentados e pensionistas, que representavam 5,36\% do PIB em 1995, reduziram-se para 4,76\% em 2009, conforme dados da Secretaria do Tesouro Nacional (STN). Além disso, as despesas com saúde e educação estão bem abaixo dos padrões internacionais dos países do OCDE. Assim como a Previdência Social está distante da universalização no Brasil, pois metade dos trabalhadores ativos está fora do sistema. 
Uma questão importante a ser destacada é que as medidas de desonerações tributárias adotadas para combater a crise afetaram o financiamento do orçamento da seguridade social, enfraquecendo a capacidade deste orçamento para cobrir com suas receitas exclusivas as despesas previdenciárias, de assistência social e de saúde.

De acordo com a Secretaria da Receita Federal do Brasil (SRFB), ao longo de 2009, o desempenho da arrecadação tributária em relação a 2009 encolheu $3,05 \%$. Em termos reais, em valores deflacionados pelo IPCA, o equivalente a uma perda de $\mathrm{R} \$ 21,5$ bilhões. Os tributos que mais contribuíram para essa queda de arrecadação foram a Contribuição para o Financiamento da Seguridade Social (Cofins) e a contribuição social para o PIS/Pasep, que são fontes importantes no financiamento da seguridade social brasileira, respondendo por 49\% do declínio da arrecadação tributária em 2009.

Essa queda na arrecadação da Cofins e do PIS/Pasep é atribuída pela Receita Federal a uma conjunção de fatores relacionados, em grande parte, à crise econômica. Em decorrência da crise ocorreu uma piora dos indicadores macroeconômicos, que influenciaram diretamente a arrecadação tributária, entre eles a produção industrial, a lucratividade das empresas e a queda no volume geral de vendas no varejo no ano de 2009 em relação a 2008. E, destacadamente, as desonerações tributárias estimadas em R $\$ 24,9$ bilhões.

Acontece que o orçamento da seguridade social continua perdendo recursos de suas fontes tributárias "exclusivas" devido à transferência de recursos para o orçamento fiscal por meio da Desvinculação das Receitas da União (DRU). A DRU transforma os recursos destinados ao financiamento da seguridade social em recursos ficais para a composição do superávit primário e, por consequência, a sua utilização em pagamento de juros da dívida.

$\mathrm{O}$ "Relatório resumido da execução orçamentária do governo federal e outros demonstrativos" divulgado pela Secretaria do Tesouro Nacional, com dados de 2009, revela que a DRU desviou do Orçamento da Seguridade Social para o Orçamento Fiscal o montante de R \$ 39,2 bilhões. Já foram surrupiados desde 2000 mais de R $\$ 300$ bilhões da seguridade social.

Além disso, com os recursos da seguridade social o governo também paga os benefícios previdenciários dos servidores públicos federais que, por princípios constitucionais, não incluiriam esse tipo de gasto. Apesar de legítimas, as despesas com inativos e com pensionistas da União devem pertencer ao 
Orçamento Geral, o qual é financiado por tributos, e não por recursos exclusivos da política de proteção social. A União transferiu para a responsabilidade do orçamento da seguridade social um estoque de gastos com aposentadorias e pensões dos servidores públicos federais que deveriam ser honrados pelo caixa do orçamento fiscal. ${ }^{8}$ As despesas com inativos e pensionistas da União pagas com recursos da seguridade social superam $\mathrm{R} \$ 50$ bilhões, o que representa $15 \%$ do montante gasto nas funções orçamentárias de previdência, assistência social e saúde.

Esse quadro pode delinear maior pressão por uma nova "reforma" na Previdência Social e por cortes no orçamento social do governo no próximo mandato presidencial. Com a volta do ataque dos conservadores aos direitos da seguridade social, especialmente na Previdência Social, como a instituição da idade mínima, o fim da vinculação dos benefícios com o salário mínimo e as mudanças nas regras das pensões, entre outros. $\mathrm{O}$ falso argumento do déficit da Previdência Social que insistentemente tem sido anunciado pelos profetas do caos (Fagnani, 2008) deve ser o tom do debate político e econômico. Os profetas do caos não mostraram nenhuma preocupação com o "equilíbrio" fiscal, quando o Banco Central voltou a aumentar a taxa básica de juros da economia no primeiro semestre deste ano. Aliás, caso seja confirmada a previsão do mercado financeiro que o aumento da taxa básica de juros chegue $11,75 \%$ neste ano, haverá um aumento de, no mínimo, R \$ 8 bilhões nas despesas do governo em $2010 \mathrm{e}$ $\mathrm{R} \$ 12,1$ bilhões no próximo ano (Khair, 2010). No final de abril a dívida pública alcançou R \$ 1,9 trilhão, sendo que 36\% dela está atrelada à Selic (taxa de juros básica da economia). Aqui reside o verdadeiro "rombo" das contas públicas brasileiras, pois o pagamento de juros e a amortização da dívida pública compromete $30 \%$ do orçamento público brasileiro. No período de 2000 a 2009 , o Fundo Público transferiu o equivalente a 45\% do PIB produzido em 2009 para os rentistas, o que seria suficiente para o governo federal custear a educação durante 40 anos, se mantido o mesmo valor gasto 2009. Ou ainda pagar por sete anos os benefícios previdenciários para mais de 23 milhões de aposentados e pensionistas.

8. No governo FHC, em 1998, foi feita uma alteração no art. 17 da Lei n. 8.212 (que dispõe sobre a organização da seguridade social e institui plano de custeio) para permitir que o pagamento dos EPUs seja feito com os recursos da seguridade social que incidem sobre o faturamento (Cofins) e com o lucro das empresas (CSLL), desde que assegurada a destinação de recursos para as ações de saúde e assistência social (Lei n. 9.711, de 20/11/1998). Porém o governo não atende plenamente as despesas da seguridade social. 


\section{Propostas para garantir os direitos sociais na crise do capital $\left.\right|^{9}$}

Como demonstrado neste artigo, o fundo público no Brasil é financiado de forma regressiva. Nesse sentido, uma verdadeira reforma tributária garantidora de direitos passa por alterações no sistema tributário, visando assegurar o caráter progressivo e redistributivo dos tributos que promova a justa distribuição de renda e de riqueza. A Proposta de Emenda Constitucional n. 233/2008, em tramitação no Congresso, deve ser rechaçada, pois sepulta o financiamento das políticas sócias. Torna-se necessário elevar a participação dos tributos diretos, ampliando a progressividade do Imposto de Renda da Pessoa Física (IRPF), tributando os lucros, dividendos e juros; instituir o Imposto sobre Grandes Fortunas (IGF) previsto na Constituição Federal de 1988 como de competência da União.

No tocante ao financiamento das políticas sociais, é necessário restabelecer, imediatamente, as bases de financiamento dos direitos sociais assegurados pela Constituição. Para tanto é fundamental:

a) Extinguir a DRU e carrear a totalidade desses recursos para a área social, em respeito aos princípios inaugurais da Carta de 1988.

b) Aplicação integral dos recursos do orçamento da seguridade social na seguridade social em cumprimento aos artigos 194 e 195 da Constituição Federal.

c) Elaboração dos orçamentos da seguridade social, fiscal e das estatais, de forma segregada, conforme o art. 165 da Constituição Federal.

d) Assegurar bases sustentadas de financiamento do Sistema Único de Saúde (SUS), com a regulamentação da Emenda Constitucional n. 29.

e) Assegurar que, a médio prazo, parte da capitalização do Fundo Soberano que está sendo constituído com recursos das taxas e royalties da exploração do pré-sal seja canalizada para o financiamento de programas sociais visando o combate à pobreza e a concentração da renda.

9. Algumas dessas propostas foram aprovadas no seminário "Direitos sociais: avanços e perspectivas", que reuniu especialistas de instituições acadêmicas, movimentos sociais e populares para refletir e debater sobre as conquistas sociais de 1988 e os novos desafios que se colocam no presente para avançar na ampliação e universalização dos direitos sociais no Brasil. Maiores informações podem ser obtidas em <www. direitosociais.org.br>. 
Em relação ao sistema de seguridade social, é urgente o cumprimento dos artigos 195 e 59 (Atos das Disposições Constitucionais Provisórias) da CF, que tratam da responsabilidade do Poder Público na "organização da seguridade social". O cumprimento da Constituição Federal exige que o planejamento das ações da seguridade seja realizado forma integrada pelos órgãos responsáveis pela saúde, pela Previdência Social, pela assistência social e pelo seguro-desemprego. No entanto, desde o final dos anos 1980, em desacordo com a Constituição, governos optaram pelo caminho da fragmentação. Recriar o Conselho Nacional de Seguridade Social (extinto em 1998) com a responsabilidade de coordenar o planejamento integrado das ações dos setores que integram a seguridade social, bem como pelo controle social sobre as fontes e usos do orçamento da seguridade social. Além da ampliação dos direitos para proteger o trabalhador face a gama variada de ameaças que o afetam, com destaque para os riscos clássicos incapacitantes do trabalho - que se potencializam na atual crise do capital -, ainda não atendidos pela proteção da seguridade social, principalmente a universalização dos direitos da Previdência e da assistência social.

Artigo recebido em ago./2010 - Aprovado em ago./2010

\section{Referências bibliográficas}

AGLIETTA, Michel. Macroeconomia financeira: mercado financeiro, crescimento e ciclos. São Paulo: Loyola, 2004.

BEHRING, Elaine. Política social: notas sobre o presente e o futuro. In: BOSCHETTI, Ivanete et al. (Orgs.). Política social: alternativas ao neoliberalismo. Brasília: UnB, Programa de Pós-graduação em Política Social, Departamento de Serviço Social, 2004. p. 161-180.

BRASIL. Presidência da República. Indicadores do sistema tributário nacional. Brasília: Presidência da República, Observatório da Equidade, 2009.

CHESNAIS, François. O capital portador de juros: acumulação, internacionalização, efeitos econômicos e políticos. In: CHESNAIS, François (Org.). A finança mundializada. São Paulo: Boitempo Editorial, 2005. p. 35-68. 
DUMÉNIL, Gérard; LÉVY, Dominique. A dinâmica da grande queda. Le monde diplomatique, agosto de 2008. Disponível em: http://diplo.uol.com.br/2008-08,a2540. Acesso em: 7 ago. 2008.

FAGNANI, E. Os profetas do caos e o debate recente sobre a seguridade social no Brasil. In: FAGNANI, E.; HENRIQUE, W.; LÚCIO, C. Previdência Social: como incluir os excluídos? São Paulo: LTr, 2008. p. 31-43.

FIORI, José Luis; TAVARES, Maria da Conceição. (Des) ajuste global e modernização conservadora. São Paulo: Paz e Terra, 1993.

HICKMANN, Clair. Quem paga a conta? Privilégio de rentistas: Imposto de Renda exclusivo na fonte. Anais do VIII Congresso Nacional dos Auditores-Fiscais (Conaf), Belo Horizonte, 13 a 19 de outubro de 2002.

HICKMANN, Clair. Princípios para uma reforma tributária cidadã. In: MORHY, Lauro (Org.). Reforma tributária em questão. Brasília: Editora da UnB, 2003. p. 10-122.

INESC. Orçamento público ao seu alcance. Brasília: Instituto de Estudos Socioeconômicos, 2006.

KHAIR, A. O rato e o elefante. São Paulo, 17 de junho de 2010. Disponível em: http:// mercadoetico.terra.com.br/arquivo/o-rato-e-o-elefante/>. Acesso: 30 jun. 2010.

LORDON, Frédéric. O mundo refém das finanças. Le Monde Diplomatique, set. 2007. Disponível em: <http://diplo.uol.com.br/2007-09,a1903>. Acesso em: ${ }^{\circ}$ out. 2008.

LUCCHESI, Cristiane. Isenção de IR estimula captação em real, Valor Econômico, 15 maio 2006, p. C1.

MANDEL, Ernest. A crise do capital: os fatos e sua interpretação marxista. São Paulo: Ensaios, 1990.

MATTOSO, Jorge. Emprego e concorrência desregulada: incertezas e desafios. In: OLIVEIRA, Jorge Eduardo e MATTOSO, Jorge Eduardo Levi (Org.). Crise e trabalho no Brasil. Campinas: Scritta, 1996.

OIT. World of Work Report 2009: The global jobs crisis and beyond/International Labour Office. Geneva: ILO, International Institute for Labour Studies, 2009.

OLIVEIRA, Francisco de. Os direitos do antivalor: a economia política da hegemonia imperfeita. Petrópolis: Vozes, 1998.

POCHMANN, Marcio. Proteção social na periferia do capitalismo: considerações sobre o Brasil. São Paulo em Perspectiva, São Paulo, v. 18, n. 2, p. 3-16, 2004. 
POCHMANN, Marcio. Gasto social, o nível de emprego e a desigualdade da renda do trabalho no Brasil. In: SICSÚ, João. Arrecadação (de onde vem?) e gastos públicos (para onde vão?). São Paulo: Boitempo, 2007. p. 69-78.

. O mito da tributação elevada no Brasil. Folha de S.Paulo, 14 set. 2008. Disponível em: <http://www1.folha.uol.com.br/fsp/opiniao/fz1409200808.htm>. Acesso em: 17 set. 2008.

SALVADOR, Evilasio. Fundo público e seguridade social no Brasil. São Paulo: Cortez, 2010.

SRFB. Análise da Arrecadação das Receitas Federais. Brasília: Secretaria da Receita Federal do Brasil, dezembro de 2009.

STN. Relatório Resumido da Execução Orçamentária do governo federal e outros demonstrativos. Brasília: Secretaria do Tesouro Nacional, 2009.

VIANNA, Salvador et al. Sistema tributário no Brasil reforça desigualdade social. Tributação em Revista, Brasília, n. 36, abr./jun. 2001.

WIZIACK, Julio. Brasil já possui 220 mil milionários, diz pesquisa. Folha de S.Paulo, 5 set. 2008. Disponível em: $<$ http://www1.folha.uol.com.br/folha/dinheiro/ult91u441681.shtml>. Acesso em: 10 jun. 2010.

ZOCKUN, Maria (Coord.). Simplificando o Brasil: propostas de reforma na relação econômica do governo com o setor privado. São Paulo: Fipe, 2005. 